\title{
Problems of Digitalization of Education in the Context of the COVID-19 Pandemic
}

\author{
N.V. Morgunova \\ Management and Marketing department \\ Vladimir State University named after Alexander \\ Grigoryevich and Nikolay Grigoryevich Stoletov \\ Vladimir, Russia \\ nmorgunova@mail.ru
}

\author{
R.V. Morgunova \\ Economics of innivation and finances department \\ Vladimir State University named after Alexander \\ Grigoryevich and Nikolay Grigoryevich Stoletov \\ Vladimir, Russia \\ morgunovarv@mail.ru
}

\author{
KHWAJA Ayham Naser \\ Tourism and Hospitality industry department \\ Chechen Federal University \\ Grozniy, Russia \\ tourism@lapost.net
}

\begin{abstract}
The article is devoted for the analyze of problems of digitalization of education in the context of the COVID-19 pandemic Information base was taken from the results of surveys of university teachers and students of several universities and monitoring data, foreign university experiences and personal practices. The main problems of transition to on-line education were defined on the base of analyses of all the data. In details we studied the information which show the reasons for being not ready for such type of education both for students and teachers. The authors underline the importance of emotional intellect which working in on-line format. It was found out that many aspects of involvement in studying are connected with the age of professors and that might be taken into consideration. One of threats of transferring to digital education was defined as loss of specialists who take part in education and don't have enough level of computer competitions. This leads to the reduction of educational quality. The authors suggested several variants for decreasing the risk of threats. Testing the proposed variants has proven the practical application of the proposed approach for saving academical potential. The methodology proposed by the authors is made according with new educational standards and higher economic efficiency of educational process.
\end{abstract}

Keywords-On-line education, COVID-19 pandemic, age, problems, adaptation, Moodle, Zoom, teaches, students

\section{INTRODUCTION}

The 21 st century is characterized by a sharp increase of online learning in all levels of education, especially in the professional one. On the one hand, there is an awareness of the need for continuous professional training and retraining throughout the life of all individuals, on the other, digital educational technologies of training are developing with an emphasis on online learning. For a professional in any subject area, the use of the digital environment has become a comfortable mandatory part of the work[1]. Educational programs of various orientation, any scope, and level are offered by universities, individual companies, Internet sites, and individuals.[2] The largest part of sales and investments is associated with programs of additional professional education.

The process of digitalization of educational services has accelerated dramatically and has grown in scale due to the COVID-19 pandemic. For example in over 270 million students being unable to return to their universities/schools just in China [3]. Most of the universities started to use various online technologies in order not to stop their educational activities. Conditions had been changed so quickly that the regulation of the implementation and realization of remote educational technologies has not been defined in Russia. The Ministry of education has given maximum freedom for universities based on specific conditions, including the experience of distance learning. Problems came from the lack or insufficiency of technical means, lack of readiness and lack of adaptability of both teachers and students, including in psychological terms. Many researchers refer to this period as a kind of test of the higher education system, but the test results and conclusions are determined by both the quality of the questions and the objectivity of the answers [4]. In this article, the authors, based on the analysis of information from official research, open press publications, monitoring data from individual universities, and their own experience, offer a modified version of the assessment of the causes of problems and ways to solve them. Current situation in Russian universities can 
be compared with the results of transition to emergency online format in other countries. [5]

\section{OBJECTS AND METHODS OF RESEARCH}

The object of research is higher education institutions in Russia, including Vladimir state University named after Alexander Grigoryevich and Nikolay Grigoryevich Stoletov, Chechen state University.

The subject of the study are the elements of mechanism of online education digitalization in the period of the COVID-19 pandemic.

\section{Method of research}

The following methods of collecting information were used:

Observation / Participant Observation

\section{Surveys}

Interviews

\section{Experiments}

The report was prepared using the results of the following studies

Analysis of students 'perception of the transition to distance learning, monitoring of the digital infrastructure of universities, interviews with teachers in April-may [6]

Analysis of the attitude of Russian University teachers to the development of the online environment in the conditions of Covid-19. [7]

A survey of students on distance learning in universities of the Russian Federation [8]

Case studies of Russian and foreign universities [9]

Analysis of monitoring of online training during the COVID-19 pandemic in VISU

Analysis of on-line training practices for teachers of IEM VISU (Instituit of Economics and Management of Vladimir state University named after Alexander Grigoryevich and Nikolay Grigoryevich Stoletov)

\section{RESULTS AND DISCUSSION}

The results of the transition of higher education institutions to a new training format show that distance learning technologies have already become an integral tool for teachers with a high probability. At the end of emergency period, many teachers plan to consult online, especially for small project groups of students, graduates, postgraduates, etc. Students have realized the possibility of accessing University courses of other specialties, which requires the development of an organizational and financial mechanism for obtaining additional courses online, but the request is there and the solution will be. Thus, the lessons of working in the context of a COVID-19 pandemic are relevant for future work
The official report concludes that teachers are not ready to conduct classes in digital format and provides facts and possible reasons for this situation are:

$60 \%$ of teachers rarely or never held their lectures and classes in the distance format or in the format of webinars, and already with the start of work in the new format, $65 \%$ of teachers think that distance learning does not allow to control the involvement of students to the necessary extent, more than $70 \%$ of teachers are afraid of increasing practices of dishonest behavior among students during exams. $88 \%$ of teachers believe that it is better to conduct classes in full-time format. $88 \%$ of teachers felt that on-line format of education for them is much more time-consumming.. Teachers note fatigue from the increased volume of work, from the difficulties of rapid development of new technologies, rapid adaptation required a lot of energy. Most users who had problems showed not enough high emotional intellect. They were not feeling the feedback from students \& that took many energy from them $\&$ hadn't given back.

The managers of online schools[10] suggest that such classes should be shorter than traditional lessons, especially for practices and groups to be sure of students' engagement. They should also be significantly smaller than the traditional size of university group, some practitioners claim that should be no more than 4-6 people. In VISU (Vladimir state University), the reduction in the duration of classes was mostly due to technical reasons - classes were conducted in the free version of ZOOM program. The standardized duration of classes was 40 minutes, followed by reconnection mainly for making individual consultations. However, such classes were not always perceived as full-fledged by students.

While agreeing with the conclusion that the difficulties were caused by the lack of information and assistance to teachers in the current regime (only $60 \%$ of universities have created special sites or sections of official sites), it is necessary to keep in mind another, more significant problem, the early signs of which have already appeared and about which nothing is said in the report of the Ministry of Education. This is a high probability of accelerating the loss of academic potential. The most experienced and qualified teachers in their discipline often, for various reasons, do not have sufficient skills to work with online environment. This also include the psychological comfort of communicating with the "blue eye" of a video camera. Such teachers need longer period to enter the process and then they conducted fewer classes, what caused dissatisfaction with the University's management and students. This factor is already taken into consideration when planned the teaching staff and the academic classes for the new teaching year. Some significant courses can be transferred to younger teachers who are less experienced in the subject area but more professionally prepared in the technological part. The quality of training will obviously decrease.

Entering the distance learning In VISU was easier due to a fairly large experience and the developed base of distance learning, which has been developing at The University for more than 10 years on the basis of the Internet site of distance learning www.dec.vlsu.ru. In IEM (Instituit of Economics and Management), distance learning groups (correspondence 
form) are formed annually in all areas of training, respectively, in all disciplines of the areas developed and posted on the website of the UMC, including both educational material and tasks and assessment tools. The site provides different possibilities for individual consultations in the educational process. Also the system for full-time and distance learning was provided on class server platform and has been functioning more then 10 years. Almost $100 \%$ of teachers (the national average of $60 \%$ ) conduct classes remotely, students perform and post the results of completed tasks, the teacher, in accordance with the approved regulations, checks the tasks, gives grades, and gives feedback. The management of the University in terms of conversion for online learning students recommend to use for submission to full-time students moodle site where in accordance with the approved rules presented by the teachers links to work programs, lecture materials, assignments, practical classes, course works, independent assignments for the semester test. A lot of work was done to provide all students with the logins and passwords allow work on the site with their personal accounts. At the same time, it was decided to conduct lectures, practical classes and consultations in online mode without restrictions for chosen platforms. The most teachers had chosen the Zoom option.

Not all results of implementing online teaching were effective, but also in east countries $49 \%$ students are in favor of studying through blended learning system which is combination of online and in-class.[11] Analysis of monitoring reports shows that many students did not join classes in a timely manner for the following reasons:

did not receive information about the new training format due to lack of access to communication channels (no Internet, poor communication quality)

did not receive information about the new training format due to lack of habit to regularly check the information account

unable to connect due to problems accessing your personal

unable to connect due to lack of available Internet and / or hardware

unable to connect to the timetable because computers are shared with parents, who also work online

students didn't connect because were not aware of the mandatory attendance in an online format and be bound by assignments and deadlines

waited to connect, because thought that format is for short period and soon be the usual training mode

connected but are unable to perform work due to misunderstanding of technology

various problems related to depression anxiety, poor internet connectivity, and unfavorable study environment at home [12].

In the same period teachers in VISU were more clearly informed and received in right time information about the need to switch to a new format of work but, like the students, not all had the technical capabilities, not all were familiar with the technology of working on online platforms, and were not ready to publish materials on the site for full-time students. Teaches need to prepare instructions, however, but it is still not an easy way to monitor and change the students' learning behaviors in such a short term [13]. For high quality of education professors need to understand different experiences of students and families living in urban and rural contexts [14]. The analysis of monitoring data in dynamics shows that the greatest positive dynamics and the percentage of students ' involvement in the educational process on remote technologies was observed in middle-aged teachers, from 35 to 50 years(Figure 1). In the groups of novice teachers and the most experienced, there is a lower proportion of involvement, which confirms the hypothesis about certain difficulties with the use of new technologies in older teachers and the lack of pedagogical competencies for involving students in younger teachers.

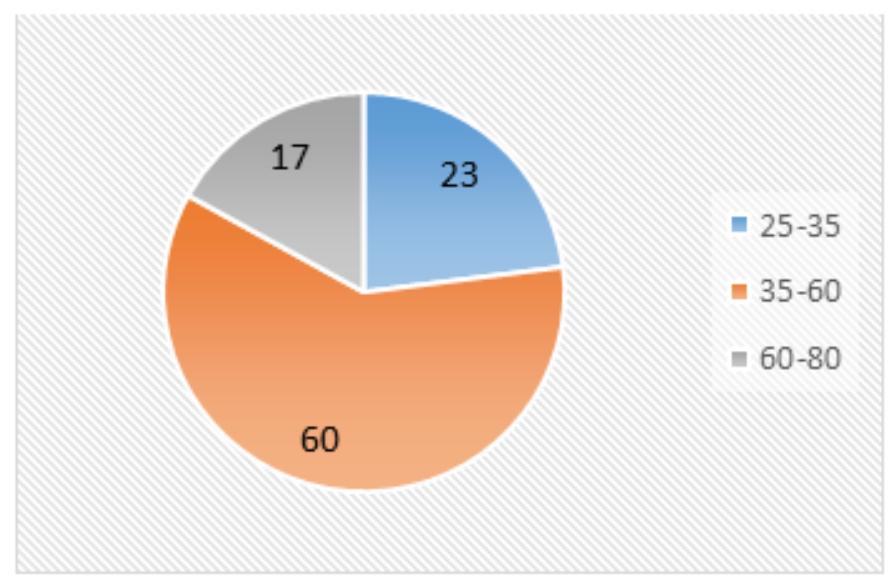

Fig. 1. \% of professors with of high involvment of students

Interviewing teachers showed that there is an increase of complexity of work due to the need to prepare special tasks for independent work on each topic. The processing and posting in the required format for distance learning site, monitoring the student's performance of tasks, checking them, preparing comments and comments for students, re-checking corrected works, maintaining additional records takes a lot of time. A significant part of these works is technical, which does not correspond to the level of qualification of an associate Professor or a University Professor. Digital technologies require, as a rule, strict implementation of regulations, a high level of attention to technical issues, when the teacher failure to comply it leads to errors and alterations. Regardless of whether faculty had previous experience teaching online or not, many faculty reported that they were using new teaching methods.[15]The teacher is forced to work on a fairly simple, but painstaking volume of work instead of a more detailed study of tasks and updating the course. This makes the work in such system not just excessive in volume, but also annoying, and the teacher is not properly motivated to perform it. The Ministry of Education suggest to improving skills and motivating the use of online technologies but it can't solve all problem. A new phenomenon has emerged - digital volunteers, it's students who help teachers with setting up and using online platforms, and technical problems. This process is connected with a question of academic integrity. In Russian 
conditions, it is difficult to expect that a student who, at the request of a teacher, will, for example, transform an examination test into the required format for the site, WILL not "merge" the answers to his classmates. At the same time, almost all universities in the Russian Federation currently have many master's programs, and in accordance with the State standard, all undergraduates must form pedagogical competencies. It is quite realistic at the level of a single University to create a mechanism and regulations for technical support from assistant undergraduates of third-party faculties to perform labor-intensive technical work related to the digitization of education. In the process of such assistance, the master's student will gain knowledge and skills related to the organization of teaching activities, and the risks of violating the principles of academic integrity can be reduced. At the same time, it is necessary to fix the need to organize and confirm online consulting for students and teachers of the University, including the methodology and technical issues of distance learning.

Analysis of monitoring and interviewees teachers and students has shown the direct connection between the level of student engagement in the educational process with the coaching support for the group (Figure 2). That can be done by a strong mayor student or a good group facilitator. This works especially well seen in master's programs, where students have a more developed system of their own motives and level of awareness. Anxiety and depression, uncertainties, intensification of the information flow pushing to negative physiological consequences of stress. [16]. However, the implementation of this approach on a large scale requires special training events to master coaching techniques for both teachers and elders, and a more conscious attitude to the appointment of curators.

\section{Involvement of students}

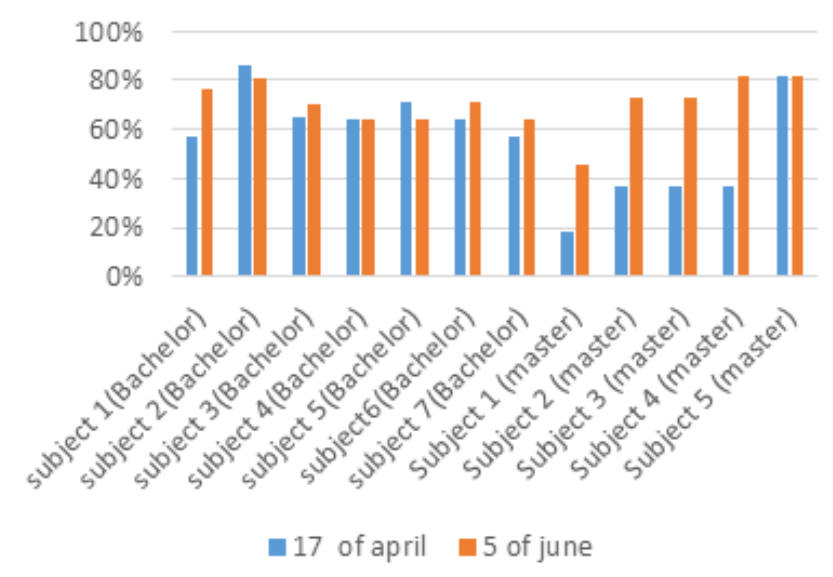

Fig. 2. Involvement of students due to level of education

As noted in many sources, student engagement often decrease in senior years of study, when a significant portion of students start to work. Their absence in university reduces the overall motivation of group. For working students from the very beginning of the course the mark is not important. Practice shows the feasibility of implementing a level approach in such situations, when the teacher, in accordance with the work program, initially brings to the students the minimum of tasks which they need to perform and to obtain a basic level. This helps to maintain the motivation of students who are focused on high grades.

Training for learning online technologies requires courses of various levels (introductory and advanced), a website with FAQ, organization online support consulting for students and teachers of the University, including the methodology and technical issues of distance learning. It also needs include social annotations of students [17].

The lack of regulation with the choice of training sites should not remove the obligation to create organizational and financial mechanisms to ensure the selection and use of online training resources. Quite a lot of University leaders followed the model which come from the Ministry, without providing teachers with technical and financial resources. The lack of available Russian platforms negatively affects the introduction of digital technologies, and initiates the creation of their own resources by individual universities, which usually do not meet the quality requirements and have limited support and development opportunities.

The current situation has led to the failure of normal new semester, so everybody needs to facilitate the later improvement and provide reference [18]. However we have to keep in mind that online migration is engendering significant dysfunctionality and disturbance to their pedagogical roles and their personal lives [19]

\section{CONCLUSION}

The research allows us to conclude that:

Digitalization of higher education in Russia has received a boost in development due to the situation with coronavirus and distance education will be in use for additional courses, Very important not to reduce the academic potential of universities by removing from teaching experienced and qualified teachers who do not have developed technological competence in distance education

Problems of teachers ' unavailability should be solved by creating appropriate technical and technological capabilities, training and motivation mechanisms, and continuous support systems

Increasing the motivation of teachers and the effectiveness of their work should be provided by the formation of a mechanism for transferring the technical part of the work to remote assistants-undergraduates in other areas of training

Ensuring the involvement of students can be implemented by coaching support from curators, teachers themselves, and old-school groups that must undergo appropriate training.

We agree with USA researches, who conclude "online learning may be useful for supporting teacher practice and suggesting future research. Developing SRL skills of students will ensure the effectiveness of online learning that the field of education may ultimately focus on in the future" $[20,21]$. So 
State Education Department must develop rules for online activity with regular lectures.

\section{References}

[1] [Mukhtar, K., Javed, K., Arooj, M., Sethi, A.57205173071:57208821335;55599732000;57117315600;Advantages, limitations and recommendations for online learning during covid-19 COVID-19 pandemic era (2020) Pakistan Journal of Medical Sciences, 36 (COVID19-S4), pp. S27-S31. Cited 1 time.https://www.scopus.com/inward/record.uri?eid=2-s2.0$85088270842 \&$ doi $=10.12669 \% 2$ fpjms.36.COVID19S4.2785\&partnerID $=40 \& m d 5=03949 d 54 c 00 a 2292 \mathrm{f} 2 \mathrm{ec} 89 \mathrm{~b} 293 \mathrm{f} 60 \mathrm{e} 62$

[2] Justin Reich and José A. Ruipérez-Valiente The MOOC pivot. Science 363 (6423), 130-131. DOI: 10.1126/science.aav7958

[3] Huang, R., Tlili, A., Chang, T.-W., Zhang, X., Nascimbeni, F., Burgos, D.7402950187;57188567626;46161064600;57216623644;57004724100 ;8937994100; Disrupted classes, undisrupted learning during COVID-19 outbreak in China: application of open educational practices and resources (2020) Smart Learning Environments, 7 (1), art. no. 19, . https://www.scopus.com/inward/record.uri?eid=2-s2.0-

$85087393747 \&$ doi $=10.1186 \% 2$ fs $40561-020-00125$ $8 \&$ partnerID $=40 \& \mathrm{md} 5=61695161413 \mathrm{dfa} 2 \mathrm{~d} 47189 \mathrm{cbef} 4 \mathrm{ef} 9 \mathrm{f} 30$

[4] Akbulut, M., Şahin, U., Esen, A.C. 57210744200;57218100682;57218108363; More than a virus: How COVID 19 infected education in Turkey? (2020) Journal of Social Science Education, 19 (Special Issue 1), pp. 30-42. https://www.scopus.com/inward/record.uri?eid=2-s2.0$85087904224 \&$ doi $=10.4119 \% 2$ fjsse3490\&partnerID $=40 \& m d 5=25813887914914 \mathrm{ff} 152 \mathrm{ffb} 29 \mathrm{~d} 678 \mathrm{db} 29$

[5] Pevneva, I., Edmunds, P. 57189255550;56331127100; Online Learning vs. Extreme Learning in Mining Higher Education under COVID (2020) E3S Web of Conferences, 174, art. no. 04001, https://www.scopus.com/inward/record.uri?eid=2-s2.0$85088517979 \&$ doi $=10.1051 \% 2 \mathrm{fe} 3$ sconf $\% 2 \mathrm{f} 202017404001 \&$ partnerID $=$ 40\&md5=ea99f8cbc363fdc1f424be7d781365dc

[6] HSE Website in the series "Modern education Analytics", no. 6 (36), $2020 \mathrm{https}: / / g o o . s u / 1 \mathrm{KPm}$

[7] Website of the Ministry of science and higher education of the Russian Federation https://goo.su/1kpO.

[8] SIA Site https://goo.su/1 Kpo

[9] HSE Website https://goo.su/1 KPo

[10] How COVID change the educational system -bi-bi-si.doc https://www.bbc.com/russian/av/media-53515725/

[11] Saif Almuraqab, N.A.57212264050; Shall universities at the UAE continue distance learning after the CoviD-19 COVID-19 pandemic? Revealing students' perspective (2020) International Journal of Advanced Research in Engineering and Technology, 11 (5), pp. 226233. https://www.scopus.com/inward/record.uri?eid=2-s2.0$85086280762 \&$ doi $=10.34218 \% 2$ fIJARET.11.5.2020.024\&partnerID $=40$ \&md5=d11fd8dbfb1dcd53a4e1824f0f745559

[12] Mohmmed, A.O., Khidhir, B.A., Nazeer, A., Vijayan, V.J. 55983064100;57217421526;57217423030;57217424683; Emergency remote teaching during Coronavirus COVID-19 pandemic: the current trend and future directive at Middle East College Oman (2020) Innovative Infrastructure Solutions, 5 (3), art. no. 72, https://www.scopus.com/inward/record.uri?eid=2-s2.0$85087204580 \&$ doi $=10.1007 \% 2$ fs41062-020-003267\&partnerID $=40 \&$ md5 $=36 f 95575538 \mathrm{bf} 14356751 \mathrm{c} 9 \mathrm{bed} 8 \mathrm{fdcba}$

[13] Chang, C.-L., Fang, M. 57214933007;57214939558; E-Learning and Online Instructions of Higher Education during the 2019 Novel
Coronavirus Diseases (COVID-19) Epidemic (2020) Journal of Physics: Conference Series, 1574 (1), art. no. 012166, https://www.scopus.com/inward/record.uri?eid=2-s2.0$85087872507 \&$ doi $=10.1088 \% 2 \mathrm{f} 1742-$

$6596 \% 2 \mathrm{f} 1574 \% 2 \mathrm{f} 1 \% 2 \mathrm{f} 012166 \&$ partnerID $=40 \& \mathrm{md} 5=\mathrm{c} 69324 \mathrm{~b} 735 \mathrm{df} 93 \mathrm{e}$ fb4829fb0b2261fed

[14] Aguliera, E., Nightengale-Lee, B. 57217361968;57217360744; Emergency remote teaching across urban and rural contexts: perspectives on educational equity (2020) Information and Learning Science, $\quad 121 \quad(5-6), \quad$ pp. $\quad 461-468$. https://www.scopus.com/inward/record.uri?eid=2-s2.0$85087135324 \&$ doi $=10.1108 \% 2$ fILS-04-20200100\&partnerID $=40 \& \mathrm{md} 5=0971894 \mathrm{~b} 5 \mathrm{a} 715 \mathrm{~b} 78453647 \mathrm{a} 65 \mathrm{ce} 756 \mathrm{fd}$

[15] Johnson, N., Veletsianos, G., Seaman, J. $57204953889 ; 18042644100 ; 57217466741 ; \quad$ U.S. faculty and administrators' experiences and approaches in the early weeks of the COVID-19 COVID-19 pandemic (2020) Online Learning Journal, 24 (2), pp. 6-21. https://www.scopus.com/inward/record.uri?eid=2-s2.0$85085954410 \&$ doi $=10.24059 \% 2$ folj.v24i2.2285\&partnerID=40\&md5=9 2b0401158929c82a6b718a3a4f4eb50

[16] Araújo, F.J.D.O., de Lima, L.S.A., Cidade, P.I.M., Nobre, C.B., Neto, M.L.R.

57216317591;57216317283;57216318205;57216323451;54882487200; Impact Of Sars-Cov-2 And Its Reverberation In Global Higher Education And Mental Health (2020) Psychiatry Research, 288, art. no. 112977, . Cited 9 https://www.scopus.com/inward/record.uri?eid=2-s2.0 85083092167\&doi=10.1016\%2fj.psychres.2020.112977\&partnerID $=40$

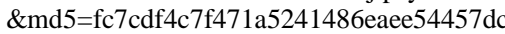

[17] Zhu, X., Chen, B., Avadhanam, R.M., Shui, H., Zhang, R.Z. 57217214067;55286416400;57217214310;57217214153;57217216257; Reading and connecting: using social annotation in online classes (2020) Information and Learning Science, 121 (5-6), pp. 261-271. https://www.scopus.com/inward/record.uri?eid=2-s2.0$85086788116 \&$ doi $=10.1108 \% 2$ fILS-04-20200117\&partnerID $=40 \& m d 5=$ ceada5c7a943296f3533734b97bd6a97

[18] .Tiejun, Z.57190128312; Empirical research on the application of online teaching in chinese colleges and universities under the situation of novel coronavirus pneumonia prevention and control (2020) International Journal of Emerging Technologies in Learning, 15 (11), pp. 119-136. https://www.scopus.com/inward/record.uri?eid=2-s2.0 85087548227\&doi=10.3991\%2fIJET.V15I1 1.13935\&partnerID=40\&m d5=098418efffc15a7c4fbd109a9a563edb

[19] Watermeyer, R., Crick, T., Knight, C., Goodall, J. 36440857400;14032736300;57203093658;24775759700; COVID-19 and digital disruption in UK universities: afflictions and affordances of emergency online migration (2020) Higher Education, https://www.scopus.com/inward/record.uri?eid=2-s2.0$85085992046 \&$ doi $=10.1007 \% 2$ fs10734-020-00561$\mathrm{y} \&$ partnerID=40\&md5=6eb7bbf6b798865ec48b696871648e 56

[20] Carter Jr, R.A., Rice, M., Yang, S., Jackson, H.A. 56893094500;56238985500;57213143638;57217233095; Self-regulated learning in online learning environments: strategies for remote learning (2020) Information and Learning Science, 121 (5-6), pp. 311-319. https://www.scopus.com/inward/record.uri?eid=2-s2.0 $85086831553 \&$ doi $=10.1108 \% 2$ fILS-04-2020 0114\&partnerID $=40 \&$ md5 $=6 \mathrm{dab} 1 \mathrm{a} 31 \mathrm{~d} 401250928 \mathrm{badf97} \mathrm{ca9}$ c718d

[21] Lall, S., Singh, N. 57216547854;57216541605; COVID-19: Unmasking the new face of education (2020) International Journal of Research in Pharmaceutical Sciences, 11 (Special Issue 1), pp. 48-53. Cited 1 time. https://www.scopus.com/inward/record.uri?eid=2-s2.085083851273\&doi $=10.26452 \% 2$ fijrps.v11iSPL1.2122\&partnerID $=40 \&$ md5=9d4b39981bc03108c7bc84c9e57f6143. 